\title{
Education Research: A Qualitative Study on Student Perceptions of Neurology and Psychiatry Clerkship Integration
}

Justin J. Mowchun, MD, MScEd, Julia R. Frew, MD, and Glenda Hostetter Shoop, PhD

Neurology ${ }^{\circledR}$ 2021;96:e472-e477. doi:10.1212/WNL.0000000000010842

\begin{abstract}
Objective

To explore student perceptions of the feasibility of neurology and psychiatry clerkship integration, including clinical education and competency evaluation, as there has been a call to improve undergraduate medical education integration of the disciplines to better develop physicians that can address nervous system disorders.
\end{abstract}

\section{Method}

Via a constructivist grounded theory approach, we carried out 5 focus groups in 2016-2017 with 28 medical students who completed both independent clerkships. Investigator triangulation was used with iterative interpretation comparisons, and themes were identified using constant comparative analysis.

\section{Results}

Three major themes arose: (1) combining the clerkships was not favorable as students need sufficient time to delve deeper into each discipline; (2) students did not observe an integrated clinical approach by faculty; (3) there is positive value to making links between neurology and psychiatry for effective patient care.

\section{Conclusions}

Students emphasized the importance of making stronger links between the 2 disciplines for their learning and to improve patient care; however, they did not observe this clinical approach in the workplace. Students perceived that integration of neurology and psychiatry clerkships should occur via increased affinity of the complementary discipline by trainees and faculty in each specialty.
Correspondence Dr. Mowchun Justin.J.Mowchun@ hitchcock.org

From the Departments of Neurology and Medical Education (J.J.M.) and Psychiatry and Medical Education (J.R.F.), Geisel School of Medicine at Dartmouth, Dartmouth-Hitchcock Medical Center, Lebanon; and Department of Medical Education (G.H.S.), Geisel School of Medicine at Dartmouth, Hanover, NH.

Go to Neurology.org/N for full disclosures. Funding information and disclosures deemed relevant by the authors, if any, are provided at the end of the article. 


\section{Glossary}

NBME $=$ National Board of Medical Examiners.

There has been a recent call to improve undergraduate medical education integration of neurology and psychiatry, to better develop physicians who can address the multidimensional manifestations of nervous system disorders. ${ }^{1}$ Closing the divide between neurologic and psychiatric patient care remains elusive, even as our emerging neurobiological knowledge reveals that many brain disorders are not due to detectable lesions, but originate from dysfunction across complex multidirectional neural networks. ${ }^{2,3}$

Curriculum integration has a theoretical foundation to promote skill acquisition while learners build deeper connections across medical disciplines. ${ }^{4,5}$ The evidence to support clerkship integration originates from longitudinal integrated clerkships. ${ }^{6}$ However, the vast majority of medical schools utilize specialty-specific clerkship blocks that reflect the dominant workplace setting of clinical teams. ${ }^{7}$ In an attempt to improve integration, some medical schools have combined their neurology and psychiatry clerkships or linked them sequentially. ${ }^{8,9}$ However, there are no reports in the literature of student perceptions of integrating neurology and psychiatry clinical education and competency evaluation. It is essential for an integrated curriculum to be perceived as relevant and timely by students. ${ }^{10}$ According to sociocultural perspectives, clerkship student learning also depends on student observations and their interactive experiences with the cultural practices, specific language, and tools of their preceptors. ${ }^{11}$ Our qualitative study aimed to explore student perceptions of psychiatry and neurology clerkship integration. We sought a better understanding of how we can improve education integration of the 2 disciplines, but also patient care for those with nervous system disorders.

\section{Method}

\section{Ethical Considerations}

This study was given exemption status by the Committee for the Protection of Human Subjects (Dartmouth College/ Dartmouth-Hitchcock Medical Center). Potential participants were informed about the voluntary nature of the study and that data would be audio recorded and analyzed anonymously.

\section{Sampling}

This qualitative study used a purposeful sampling strategy of 5 focus group sessions with 28 fourth-year medical students (16 female, 12 male) who had completed both independent psychiatry and neurology clerkships at the Geisel School of Medicine at Dartmouth. One researcher (G.H.S.) sent recruitment emails to students who were about to complete their second of the 2 clerkships (neurology, $n=38$ ). All of our medical students complete their required 6-week inpatient psychiatry clerkship during their third year, and almost all students complete their required 4-week primarily inpatient neurology clerkship in their fourth year. The 60-minute focus groups took place at Dartmouth-Hitchcock Medical Center in Lebanon, New Hampshire, from July 2017 through January 2018 on the final day of a neurology clerkship.

As data analysis progressed, we also targeted specific students who were not available when they completed their neurology clerkship as they were rotating at away sites. We also invited 3 students completing their neurology subinternship at Dartmouth-Hitchcock Medical Center, who had completed both clerkships the previous academic year. These additional students were thought to help advance our understanding of developing categories and emerging theory as the focus groups were iteratively analyzed. ${ }^{12}$ The majority of students completed their clerkships at Dartmouth-Hitchcock Medical Center. Our other students completed their clerkships at 3 nearby affiliated sites and at California Pacific Medical Center in San Francisco, where we have away rotations. The focus groups had 4-8 students per group. Group sizes were dependent on variable clerkship enrollment. The optimal size of a focus group is between 6 and 10 participants, ${ }^{13}$ but a minimum of 3-4 participants is sufficient. ${ }^{14}$

\section{Data Collection and Analysis}

Focus groups were used to facilitate student interaction to gain depth and interconnections in the exploration of the topics. ${ }^{15}$ The moderator (G.H.S.) had background knowledge of the neurology and psychiatry clerkships but was not involved in clerkship student education or evaluation. Semistructured interview questions were created based on important concepts of neurology and psychiatry clerkship curriculum integration. ${ }^{5,6,8,9}$ G.H.S. facilitated the discussion using a list of questions for guidance (table).

The focus groups were audio recorded and verbatim transcripts were created. Focus groups and analyses were conducted iteratively to facilitate the expansion of categories in later focus groups. Focus group data were compared within each group and among the other groups. ${ }^{16}$ The primary approach for data interpretation was via a constructivist grounded theory approach. ${ }^{17}$ In this process, we iteratively explored how and why our students constructed meaning in specific contexts. We worked to develop more of a partnership with our participants, which facilitated a mutual construction of meaning during the focus groups, and reconstruction of student stories as openly as possible into a grounded theory approach. ${ }^{18}$ Investigator triangulation was used with interpretation comparisons among the authors J.J.M. and J.R.F., and major themes emerged after discussion of the codes. 


\section{Table 1 Focus Group Interview Guide}

What are your perceptions of the strengths and limitations of psychiatry and neurology clerkship integration? (Prompt: Perception of a combined clerkship vs a block clerkship that occurs sequentially vs keeping the clerkships in separate years)

What are your perceptions of psychiatry and neurology clerkship faculty working together to integrate the disciplines and the multidimensional manifestations of nervous system and psychiatric presentations? (Prompts: Small group settings/case-based learning in a combined clerkship or possibly faculty teaches sessions in each other's clerkships that are linked sequentially; Any particular clinical presentations where you would find a more integrated approach helpful?)

What are your perceptions of competency-based assessment and grading integration of these clerkships? What are your perceptions of the strengths and limitations of combining these or having them separate?

Emerging themes were discussed and reviewed with G.H.S. and final theme consensus was reached. Theoretical sufficiency was determined by the authors after analysis of the fifth focus group. We determined sufficiency when we had enough data for a clear understanding of our essential themes without gaps in our analysis. ${ }^{19}$ Member checking was used to reduce bias of the data analysis. ${ }^{20}$ G.H.S. emailed all of the study participants with the preliminary themes, about 2 months after the final focus group, to provide them an opportunity to assess the adequacy of the results. Students were asked to communicate any concerns of misinterpretation or additional considerations about the findings to G.H.S., and no specific feedback was received. It is important to recognize that our students may have been hesitant to provide constructive feedback based on the time lag between data collection from their focus group and final analysis of all transcripts, as well as their possible perceptions of expertise of the researchers. ${ }^{19}$

\section{Results}

Three major themes arose: (1) combining the clerkships was not favorable as students needed sufficient time to delve deeper into each discipline to make links for deeper learning; (2) observations of a nonintegrated clinical approach by psychiatry and neurology faculty; (3) positive value of making links between neurology and psychiatry for effective patient care. We present the results supported by distinctive quotes from the focus groups (labeled FG), organized according to themes, and described in relation to our conceptual framework (figure).

\section{Perceived Effects of Combining the Clerkship and Student Learning}

Although students emphasized the importance of having both clerkships in the third year of medical school, combining them was not favorable to most students as they had concerns that this method of integration of complex material might inhibit learning.

\footnotetext{
"Right off the bat, the first thing I thought about was length and how you are supposed to master both the psychiatric interview as well as something like the neurological exam. I feel like that might be a difficult thing to do at the same time." (FG2)
}

"I learned at a much deeper level when I could just do psychiatry. And not have to worry about memorizing the tracks for neurology and going back and forth between the physical exam and the psychiatric exam..." (FG5)

Students also perceived barriers to implementation of a more holistic combinatory form of integration, which included multiple clinical services and sites, as well as concerns for integrated assessments. Students emphasized significant concern on how to integrate high-stakes National Board of Medical Examiners (NBME) neurology and psychiatry examinations. They recognized some content overlap for these examinations, but had anxiety about combining the examinations or taking them in close proximity to each other.

"...but there was a lot of neuro on the psych shelf that I remember."

(FG2)

"...how the shelf would look because you would take two shelves at the end? That would be super stressful if they were integrated." (FG1)

Some students did see opportunities for faculty observation of their clinical skills, and described potential links between psychiatry and neurology core examination skills.

"...one benefit would be that technically the mental status exam has a lot of similarities between the two, maybe not all things but that would be one other reason to think that you could teach them at the

Figure Student Considerations and Associated Influences on Neurology and Psychiatry Clerkship Integration Identified Through Thematic Analysis

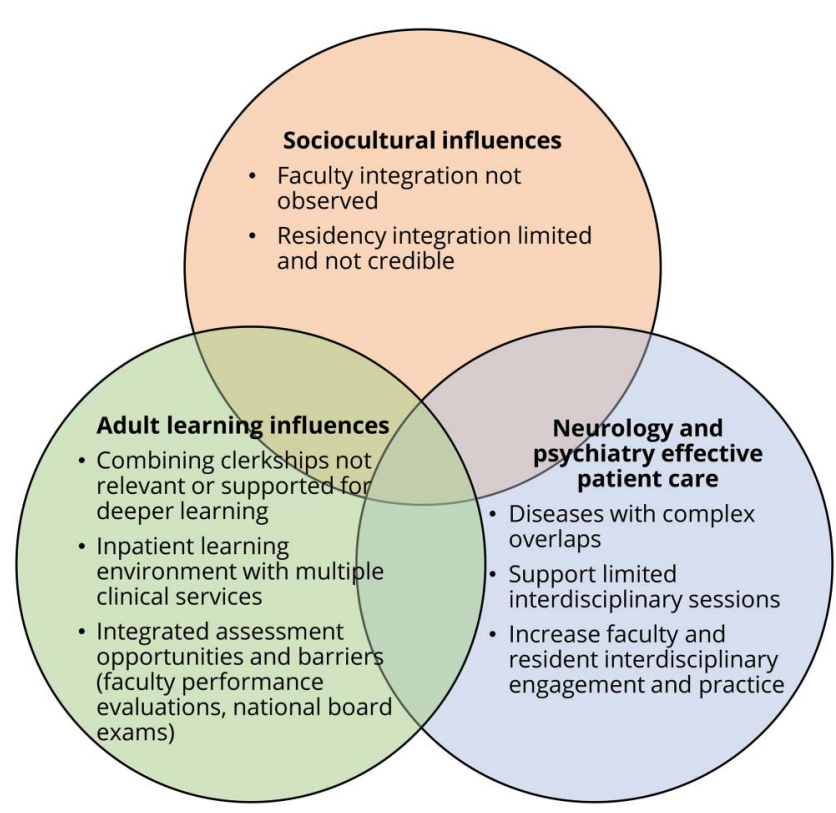

Student considerations for neurology and psychiatry clerkship integration based on 5 focus groups from July 2017 through January 2018 with 28 medical students who completed both independent clerkships. Students perceived complex system-based overlaps among learning, assessment, and sociocultural influences when training to care for patients with nervous system disorders. 
same time and say this is a more neurologically focused mental status exam and this is a psychiatrically focused mental status exam..." (FG3)

Students perceived that high-stakes summative clinical performance evaluations may penalize learners who integrate their skills, even if they provide more effective care for their patients. Students recognized a clear lack of a shared mental model of integration by psychiatry and neurology faculty for student clinical performance evaluations.

"I just think the things that the people who are evaluating value on the clerkships are completely different. Like the things that a psychiatrist might mark me high for a neurologist might mark me low for. So I don't know how well they would go together." (FG2)

"From a skills-based standpoint of what you're supposed to derive from each of these clerkships, I think that they're very disparate in that respect. So, I think that, at least in my experience, psychiatry was a clerkship in which you really honed your interviewing skills...and, I think neurology is not the opposite in the sense that there isn't an interview component, but it really is, I think, one of your greatest experiences in using the physical exam. And, I think that's where the integration would hit a pretty hard stop..." (FG4)

\section{Integrated Clinical Approach by Faculty Not Observed}

Although students did see a benefit of making some links between the 2 clerkships for their learning, a significant barrier to integration on any level is that students did not observe this clinical approach among psychiatry and neurology faculty and residents.

\begin{abstract}
"I think the aspiration to teach and to have students experience these two disciplines in tandem is really good, because they are really related... when I was in my rotation, a lot of providers do not really make the connections that they could be making. To have students go in there with the expectation that they are going to be combining these two disciplines to a better extent that they currently are, when the practice really is not..." (FG1)

"We are in two different worlds..." (FG3)
\end{abstract}

Students perceived that psychiatry and neurology residents rotating on each other's services opens opportunities for clerkship integration and facilitates broader perspectives for patient care, but currently is too superficial and limited to be credible.

\footnotetext{
"Often times you would turn to him in rounding and be like, "What do you think?' Maybe if that were more of a widespread experience, and also from the other direction..." (FG1)

"In the conversation that we are having, we are trusting a 1-week intern to be the psychiatrist. That just also demonstrates that they are not really prepared to have those collaborations across disciplines, even though I do think it was helpful and it was beneficial. There is room for that." (FG1)
}

\section{Positive Value of Making Links Between Neurology and Psychiatry for Effective Patient Care}

Students recognized the value of making links for effective patient care, which they emphasized for diseases that have strong but complex overlaps between the 2 disciplines, such as dementia, Parkinson disease, and epilepsy or seizures.

"(In) some people it is a mixed seizure. Some people have epilepsy, but they also have pseudo seizures..." (FG2)

Students supported piloting limited integrated sessions on both clerkships as a clear opportunity to explore these links.

"It could be whatever topics come up that really follow the middle of the pie chart for both. I think it could be cool to have 2 sessions where it is combined. It would probably be 1 neurologist and 1 psychiatrist going over it together. You could offer that in both clerkships." (FG3)

Students also emphasized the importance of clear goals and careful implementation of any interdisciplinary session, where discussion of the complex links essential for patient care can be explored by faculty prepared to discuss these links.

\begin{abstract}
"I think the value of doing a joint session of some type would have to be a little bit more focused on what it is like to take care of these people, and less about teaching at the same time because it would be weird to be, 'I am going to teach you about dementia.' 'No, I am going to teach you about dementia.' I think it would better to be like, 'This is my experience with taking care of a patient with dementia. These are the challenges we face and things we are able to do' and see that from both sides." (FG1)
\end{abstract}

\section{Discussion}

Students perceived that combining the neurology and psychiatry clerkships would be inhibitory for their learning. Our students valued sufficient time to delve deeper in each discipline to make links for deep learning. Students perceived barriers to implementation that included multiple clinical services and trepidation for integrated assessments (including specialty-specific NBME examinations and faculty performance evaluations). Integration can enhance learning when a curriculum calls upon students to establish connections, but time-linked schedules are not an integration panacea. ${ }^{21}$ Students may also feel anxiety in an integrated curriculum if they are uncertain of the width and depth of the subject while studying for discipline-specific examinations. ${ }^{22}$ One combined neurology and psychiatry clerkship showed a negative effect on NBME examination scores compared to when these clerkships were independent. ${ }^{23}$ Student workplace-based performance evaluations are also emphasized in clerkships and it is essential to address student concerns of psychiatry and neurology faculty variability on what they judge as important for student competency. Clerkships and their teaching faculty must build and communicate to students a shared model of clinical performance evaluation. ${ }^{24,25}$ This process should include frequent direct observation assessments of students, coupled with performance feedback, to facilitate guided practice for safe, effective, and patient-centered care. ${ }^{26}$ Based on our student perceptions, we suggest that psychiatry and neurology faculty should incorporate components of each other's clinical skills to facilitate clerkship integration, while augmenting patient care. Trainee direct 
observation is important for high-quality patient care at the point of care, but requires effective faculty development. ${ }^{27}$

The sociocultural lens of clerkship student learning and assessment, which reflects the complex clinical workplace, is also important to consider. ${ }^{28}$ Sociocultural perspectives situate learning within specific contexts and cultures, and as a social process. ${ }^{29}$ Medical student learning depends on their interactive experiences with faculty and the meaning they attach to these experiences. ${ }^{11}$ This framework has been applied to longitudinally integrative and primary care clerkships ${ }^{6,11}$ where the outpatient environment can create the developmental space for trainees to be able to learn and develop their professional identity. ${ }^{11}$ Although our students saw a benefit of making links between the disciplines for their learning, a significant barrier to clerkship integration is that students did not observe an integrated clinical approach among psychiatry and neurology faculty and residents. Students described that psychiatry and neurology residents rotating on each other's services opened opportunities for clerkship integration and facilitated broader perspectives for patient care. However, these opportunities in the clinical learning environment were perceived by students as sporadic and insufficient to be credible. Longitudinal psychiatry and neurology residency training, as recommended for psychiatric training in primary care, ${ }^{30}$ would be a positive step for integration. Family practice residencies provide more longitudinal workplace psychiatric training with higher resident satisfaction in their psychiatry training compared to internal medicine and pediatric residency programs. ${ }^{31}$ Another recent study found board-certified psychiatrists were less satisfied with their neurology training than their primary care training and they wanted longitudinal neurology training in all years of their residency. ${ }^{32}$ A similar survey to board-certified neurologists concluded that most were not very satisfied with their psychiatry training in contrast to their primary care training, and only one third felt highly prepared for practice from the psychiatry aspect of patient care. ${ }^{33}$ These neurologists desired more longitudinal experience with psychiatry teams and more outpatient care. One suggestion by our students was increasing presence of senior neurology and psychiatry residents on each other's consultation services, and allowing clerkship students to rotate with those integrated teams with prepared faculty.

Subspecialists in behavioral neurology and neuropsychiatry have made calls to lead neurology and psychiatry integrative care in the clinical learning environment. ${ }^{2,34}$ However, we suggest, based on our students' perceptions, that all psychiatry and neurology trainees and faculty need to take an active role to facilitate a culture of integration. Neurology faculty may not be comfortable with their own psychiatric interview, mental status examination, diagnostic formulation, and management skills when relevant for their patients. ${ }^{2}$ Faculty development can facilitate focused competency in integrated patient care, and provide the tools to help faculty train their learners. ${ }^{27}$ The neurology Accreditation Council for Graduate Medical Education milestones for psychiatric patient care may also help provide a common language to support faculty development integrative initiatives. ${ }^{1}$ Innovative programs can be implemented with minimal faculty time commitments such as focused podcasts. ${ }^{35}$ Neurology clerkships could partner with their psychiatry colleagues in order to create focused reviews of essential topics. A faculty development curriculum has been published for teaching the psychiatric interview and mental status examination to medical students, ${ }^{36}$ which could be modified and implemented by neurology faculty to augment their integrative teaching skills.

The classroom context can be a starting point for psychiatry and neurology programs wanting to improve clerkship integration. Our students recognized the positive value of making interdisciplinary links for effective patient care, which they perceived as particularly relevant for diseases such as dementia, Parkinson disease, and epilepsy. Students supported piloting limited interdisciplinary integrated sessions on both clerkships to advance the culture away from discipline silos. According to sociocultural learning perspectives, integrated sessions can be disruptive experiences that may catalyze change in cultural norms. ${ }^{37}$ A longitudinal integrated clerkship described interdisciplinary teaching as an ideal instructional approach for integrated clerkship didactics. ${ }^{38}$ Limited multidisciplinary casebased sessions on psychiatry and neurology clerkships could be trialed where faculty discuss important overlaps together. These sessions may also help catalyze change in neurology and psychiatry cultural workplace norms, which is essential for effective clerkship integration.

\section{Limitations}

Limitations of this study include that our sample of students was from 1 US medical school, which may not be transferrable to other institutions; however, students who participated completed their clerkships at multiple different sites. Our students had limited outpatient experiences that may have affected their perceptions of neurology and psychiatry clerkship integration. Block clerkships that emphasize the outpatient setting, as successfully utilized in longitudinal integrated clerkships, ${ }^{39}$ may offer other patient opportunities that could impact student perceptions of clerkship integration. The study also only sought student perceptions; faculty and resident perceptions of psychiatry and neurology clerkship integration would also be important to explore. J.J.M. and J.R.F. had direct but limited contact with many of the students through their respective clerkships, which carried potential reflexive effects. However, the focus groups were carried out by G.H.S., who was not directly involved with the clerkships.

\section{Conclusions}

Students perceive the importance of making stronger links between neurology and psychiatry for their learning and to improve patient care; however, a significant barrier is that they do not observe this clinical approach in the workplace. Students perceive that improved integration of neurology and psychiatry clerkships starts with increased engagement of the complementary discipline by trainees and faculty in both 
specialties. For medical education programs, both undergraduate and graduate, a response to this call from students will not be easy. In order to move forward in psychiatry and neurology clerkship integrative education to best meet societal demands in the common block clerkship formats, medical training programs will require focus on the system and sociocultural factors in workplace learning. Quality improvement in this dynamic context will train students for complex neuropsychiatric presentations and facilitate a continuous commitment in the clinical environment that best integrates the disciplines to care for patients.

\section{Study Funding}

No targeted funding reported.

\section{Disclosure}

The authors report no disclosures relevant to the manuscript. Go to Neurology.org/N for full disclosures.

\section{Appendix Authors}

\begin{tabular}{lll}
\hline Name & Location & Contribution \\
\hline $\begin{array}{l}\text { Justin J. } \\
\text { Mowchun, } \\
\text { MD }\end{array}$ & $\begin{array}{l}\text { Department of Neurology, } \\
\text { Dartmouth Hitchcock- } \\
\text { Medical Center, Lebanon, } \\
\text { NH }\end{array}$ & $\begin{array}{l}\text { Conceptualization of the } \\
\text { study, data analysis, } \\
\text { drafting of the manuscript }\end{array}$ \\
\hline $\begin{array}{l}\text { Julia R. } \\
\text { Frew, MD }\end{array}$ & $\begin{array}{l}\text { Department of Psychiatry, } \\
\text { Dartmouth Hitchcock- }\end{array}$ & $\begin{array}{l}\text { Major role in data analysis, } \\
\text { revising the manuscript for } \\
\text { intellectual content }\end{array}$ \\
$\begin{array}{l}\text { Medical Center, Lebanon, } \\
\begin{array}{l}\text { Glenda } \\
\text { Hostetter } \\
\text { Shoop, } \\
\text { PhD }\end{array}\end{array}$ & $\begin{array}{l}\text { Department of Medical } \\
\text { Education, Geisel School of }\end{array}$ & $\begin{array}{l}\text { Major role in acquisition of } \\
\text { the data, data analysis, } \\
\text { revising the manuscript for } \\
\text { intellectual content }\end{array}$ \\
\hline
\end{tabular}

\section{References}

1. Taylor JJ, Williams NR, George MS. Beyond neural cubism. Acad Med 2015;90: 581-586.

2. Perez DL, Keshavan MS, Scharf JM, Boes AD, Price BH. Bridging the great divide: what can neurology learn from psychiatry? J Neuropsychiatry Clin Neurosci 2018;30: 271-278.

3. Martin JB. The integration of neurology, psychiatry, and neuroscience in the 21st century. Am J Psychiatry 2002;159:695-704.

4. Benor DE. Interdisciplinary integration in medical education: theory and method. Med Educ 1982;16:355-361

5. Brauer DG, Ferguson KJ. The integrated curriculum in medical education: AMEE Guide No. 96. Med Teach 2015;37:312-322.

6. Teherani A, Irby DM, Loeser H. Outcomes of different clerkship models. Acad Med 2013;88:35-43.

7. Gheihman G, Jun T, Young GJ, et al. A review of longitudinal clinical programs in US medical schools. Med Educ Online 2018;23:1444900.

8. Safdieh JE, Quick AD, Korb PJ, et al. A dozen years of evolution of neurology clerkships in the United States: looking up. Neurology 2018;91:e1440-e1447.

9. Griffeth BT. The successful integration of psychiatry and neurology in a combined clerkship. Acad Psychiatry 2017;41:547-550.
10. Taylor DCM, Hamdy H. Adult learning theories: implications for learning and teaching in medical education: AMEE guide no. 83. Med Teach 2013;35: e1561-72.

11. van der Zwet J, Zwietering PJ, Teunissen PW, van der Vleuten CPM, Scherpbier AJJA. Workplace learning from a socio-cultural perspective: creating developmental space during the general practice clerkship. Adv Heal Sci Educ 2011;16:359-373.

12. Coyne IT. Sampling in qualitative research: purposeful and theoretical sampling; merging or clear boundaries? J Adv Nurs 1997;26:623-630.

13. Barbour RS. Making sense of focus groups. Med Educ 2005;39:742-750.

14. Stalmeijer RE, McNaughton N, Van Mook WNKA. Using focus groups in medical education research: AMEE guide no. 91. Med Teach 2014;36:923-939.

15. Parker A, Tritter J. Focus group method and methodology: current practice and recent debate. Int J Res Method Educ 2006;29:23-37.

16. Kolb SM. Grounded theory and the constant comparative method: valid research strategies for educators. J Emerg Trends Educ Res Policy Stud 2012;3:83-86.

17. Watling CJ, Lingard L. Grounded theory in medical education research: AMEE guide no. 70. Med Teach 2012;34:850-861.

18. Mills J, Bonner A, Francis K. Adopting a constructivist approach to grounded theory: implications for research design. Int J Nurs Pract 2006;12:8-13.

19. Varpio L, Ajjawi R, Monrouxe LV, O’Brien BC, Rees CE. Shedding the cobra effect: problematising thematic emergence, triangulation, saturation and member checking. Med Educ 2017;51:40-50.

20. O’Brien BC, Harris IB, Beckman TJ, Reed DA, Cook DA. Standards for reporting qualitative research: a synthesis of recommendations. Acad Med 2014;89: $1245-1251$.

21. Harden RM. The integration ladder: a tool for curriculum planning and evaluation. Med Educ 2000;34:551-557.

22. Bandaranayake RC. The Integrated Medical Curriculum. London, UK: Radcliffe Publishing Ltd.; 2011.

23. Anderson HS, Gabrielli WF, Paolo A, Walling A. Independent or Integrated? the impact on subject examination scores of changing a neuropsychiatry clerkship to independent clerkships in psychiatry and neurology. Acad Psychiatry 2017;41: 510-512.

24. Albanese MA. Challenges in using rater judgements in medical education. J Eval Clin Pract 2000;6:305-319.

25. Bowe CM, Armstrong E. Assessment for systems learning: a holistic assessment framework to support decision making across the medical education continuum. Acad Med 2017;92:585-592.

26. Holmboe ES. Realizing the promise of competency-based medical education. Acad Med 2015;90:411-413.

27. Kogan JR, Conforti LN, Iobst WF, Holmboe ES. Reconceptualizing variable rater assessments as both an educational and clinical care problem. Acad Med 2014;89: 721-727.

28. Bleakley A. Broadening conceptions of learning in medical education: the message from teamworking. Med Educ 2006;40:150-157.

29. Billett S. Learning through health care work: premises, contributions and practices. Med Educ 2016;50:124-131.

30. Hodges B, Inch C, Silver I. Improving the psychiatric knowledge, skills, and attitudes of primary care physicians, 1950-2000: a review. Am J Psychiatry 2001;158: $1579-1586$.

31. Leigh H, Stewart D, Mallios R. Mental health and psychiatry training in primary care residency programs: part I: who teaches, where, when and how satisfied? Gen Hosp Psychiatry 2006;28:189-194.

32. Juul D, Lyness JM, Thomas CR, Faulkner LR. Primary care and neurology in psychiatry residency training: a survey of early career psychiatrists. Acad Psychiatry 2019; 43:51-55.

33. Gutmann L, Adams HP, O'Shea S, Juul D, Faulkner L. Early career neurologists' feedback about the primary care and psychiatry components of residency training. Neurology 2017;88(suppl 16):P1.040. Abstract.

34. Benjamin S. Neuropsychiatry and neural cubism. Acad Med 2015;90:556-558.

35. Bernstein J, Mazotti L, Ann Ziv T, et al. Texting brief podcasts to deliver faculty development to community-based preceptors in longitudinal integrated clerkships.MedEdPORTAL 2018; 14:10755.

36. Ahuja T, Fornari A. Early psychiatry experience faculty development: preparing preceptors to facilitate patient interviews by second-year medical students with debrief. MedEdPORTAL 2016. Available at: mededportal.org/doi/10.15766/mep_ 2374-8265.10350. Accessed May 24, 2020.

37. Kahlke R, Bates J, Nimmon L. When I say ... sociocultural learning theory. Med Educ 2019;53:117-118.

38. Mazotti LA, O’Brien BC, Kirsch HE. Improving integration of clinical clerkship didactic curriculum. Med Educ Dev 2011;1:e1-3.

39. Hauer KE, Hirsh D, Ma I, et al. The role of role: learning in longitudinal integrated and traditional block clerkships. Med Educ 2012;46:698-710. 


\section{Neurology}

\section{Education Research: A Qualitative Study on Student Perceptions of Neurology and Psychiatry Clerkship Integration}

Justin J. Mowchun, Julia R. Frew and Glenda Hostetter Shoop

Neurology 2021;96;e472-e477 Published Online before print September 9, 2020

DOI 10.1212/WNL.0000000000010842

This information is current as of September 9, 2020

\section{Updated Information \&} Services

References

Subspecialty Collections

Permissions \& Licensing

Reprints including high resolution figures, can be found at: http://n.neurology.org/content/96/3/e472.full

This article cites 37 articles, 1 of which you can access for free at: http://n.neurology.org/content/96/3/e472.full\#ref-list-1

This article, along with others on similar topics, appears in the following collection(s):

All Clinical Neurology

http://n.neurology.org/cgi/collection/all_clinical_neurology All Education

http://n.neurology.org/cgi/collection/all_education

All Psychiatric disorders

http://n.neurology.org/cgi/collection/all_psychiatric_disorders

Information about reproducing this article in parts (figures,tables) or in its entirety can be found online at:

http://www.neurology.org/about/about_the_journal\#permissions

Information about ordering reprints can be found online:

http://n.neurology.org/subscribers/advertise

Neurology ${ }^{\circledR}$ is the official journal of the American Academy of Neurology. Published continuously since 1951, it is now a weekly with 48 issues per year. Copyright @ 2020 American Academy of Neurology. All rights reserved. Print ISSN: 0028-3878. Online ISSN: 1526-632X.

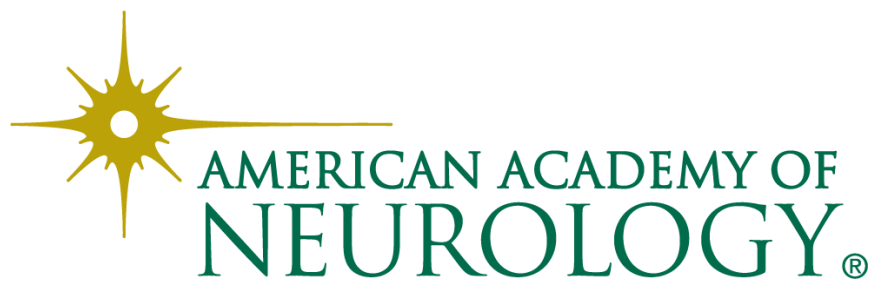

